\title{
Stitching and unpicking
}

ambivalence toward womanhood

and maternity in works by

Ilené Bothma

\author{
$>\quad$ Irene Bronner \\ Senior Lecturer with the NRF South African Research Chair in South African Art and Visual Culture, \\ FADA, University of Johannesburg, Johannesburg, South Africa. \\ ireneb@uj.ac.za (ORCID: https://orcid.org/0000-0002-1199-9636)
}

Published by

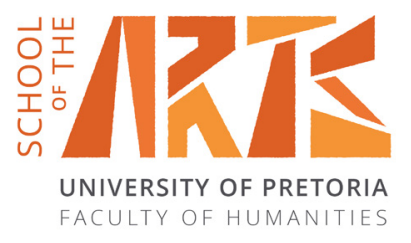

\begin{abstract}
Ilené Bothma knits with nylon stockings, stitches with human hair, and performs interventional actions with household furniture. Many of her canvases are vintage handkerchiefs and stockings. The body - specifically female and maternal bodies - is everywhere signalled, but seldom present. The artist also produces meticulously detailed, naturalistic paintings of her own and others' knitting, embroidery and crochet. Her delicate patterning with hair and her paintings of fabric soiled by bodily fluids provide a reflective tension within her work that speaks to how narratives of gendered roles and identities are written into representation. What the artist calls her 'deliberately bad knitting' is central here (Bothma 2020b). Bothma also creates a narrative for the work itself, encouraging possibilities for the interpretation of creative labour. As Valerie Mainz and Griselda Pollock (2000:3) put it, 'attention [is] given here to the work process by which an image is itself produced'. What emerges is a foregrounding of women's ambivalence.
\end{abstract}

Keywords: Ilené Bothma, South African feminist, Maternity, Abject; Knitting, Textile art. 
Ilené Bothma was born in 1981 in Port Elizabeth and currently lives and works in Cape Town, with her partner and two young children. Her most recent solo exhibition was The Theatre of the Mother Cord at 99 Loop Gallery in Cape Town in 2017. ${ }^{1}$ Because no scholarly work ${ }^{2}$ has been published as yet on Bothma's oeuvre, I introduce in this article a variety of her works that incorporate textiles, emphasising her diverse use of materials and her interpretations on the themes of womanhood, motherhood and femininity. My interpretation here is influenced by Bothma's own declared interest in the abject, in a Kristevan sense of the term, as a means of framing her oeuvre (Bothma 2020b). It is from a relationship with the abject that the artist introduces a particular quality of story-telling, of presenting a testifying narrative that remains - in some ways, dangerously - open-ended. Ambivalence and conflicting emotions - fear, awe, rage, love, defiance, discomfort, frustration - towards the "maternal", the "womanly" and the "artistic" are explored by various techniques that enact the "time-consuming, seemingly endless repetition of trifling tasks' involved in housework and childcare (Bothma 2020b).

Ilené Bothma's abject: Domestic labour and the maternal imaginary

Bothma's affinity with the Kristevan concept of the abject bears some elaboration in order to lay the groundwork for a sustained engagement with her textile-based works. Julia Kristeva (1982:4), a French literary feminist of the later twentieth century, in her seminal book, Powers of Horror, defined the causes and condition of abjection as 'not lack of cleanliness or health ... but what disturbs identity, system, order. What does not respect borders, positions, rules [what draws attention to] the "fragility of the law"'. No substance or situation is "inherently", unconditionally abject: rather it is the human reaction - in the form for instance of horror or vomit - that responds to a perceived threat of a breakdown in meaning. ${ }^{3}$ The abject may therefore be understood as whatever must be gotten rid of (in other words, abjected) in order to maintain the integrity of the subject ("l") and form ("my body"), in other words, what is perceived as subverting rules of subjecthood and society.

Mary Douglas's anthropological reading of dirt is foundational to Kristeva's working definition of abjection, that Kristeva goes on to deploy principally in analysing Biblical texts. Douglas's observation that dirt as a concept is 'matter out of place' establishes the transitionary nature of the abject (Douglas cited by Kristeva 1982:7). She proposes the corpse as the ultimate in abjection - 'death infecting life' - as it dramatically exposes the porousness of literal and symbolic boundaries, being neither subject nor object (Douglas cited by Kristeva 1982:7). Similarly, Douglas (cited by Kristeva 1982:4) highlights that '[s]pittle, blood, urine, faeces or tears by simply issuing forth have traversed the boundary of the body'. Kristeva explores how the abject in the arts appears 'on the fragile 
border (borderline cases) where identities (subject/object, and so forth) do not exist or only barely so - double, fuzzy, heterogeneous, animal, metamorphosed, altered, abject' (Kristeva 1982:207). ${ }^{4}$ Crucially therefore, although I reject it, I can never discard it: the relationship to the abject is always one of unbearable intimacy.

Female bodies and female subjects have historically been defined as abject. Their disciplining and constraint usually result because a dominant ideology perceives some aspect of their bodies, beings or expressions as threatening to the integrity of the ideology's tenets, in other words, as abject. In a patriarchal society, for instance, women who demonstrate economic, intellectual, emotional and reproductive independence of male authority figures threaten the defined boundaries of the society. Those boundaries are subsequently defended, and the women are in some way acted upon so that their power or influence is perceived as having been reduced. In western art and culture, the classical ideal of the unity and integrity of form has had a lasting effect. Art historian Lynda Nead's seminal book, The Female Nude (1992), examines strategies by which female bodies and psyches are defined as "leaking", "wanton", "unsymmetrical" and "unregulated" and are thus in need of "ordering" and "containing" by the forms, conventions and poses of classical and western art in a triumph of "culture" over "nature". As Nead (1992) writes,

If the female body is defined as lacking containment and issuing filth and pollution from its faltering outlines and broken surface, then the classical forms of art perform a kind of magical regulation of the female body, containing it and momentarily repairing the orifices and tears.

Those bodies that defy these boundaries thus reveal and subvert them. In so doing, they resist the regulatory and controlling gaze of a culture's dominant authority.

Feminist artists employ numerous strategies in these forms of defiance and critique, such as subject matter that privileges experiences particular to women's lives and challenges the historic elevation of so-called "high art" techniques and mediums over those of socalled "craft" and other non-traditional mediums (in which female practitioners, for various reasons, historically have been better represented than males). ${ }^{5}$ Bothma employs both these strategies to render strange ${ }^{6}$ the domestic. Her work displays a relish in as well as an assessing manipulation of the possibilities afforded by domesticity's abject substances and processes - possibilities for the subversion of restrictive social norms but also possibilities for the expression of the artist's own ambivalent feelings. Working into, working with, issues of the feminine and the maternal risk reverting to - or being accused of reverting to - essentialist tropes that reduce female subjectivities to supposed biological imperatives, dovetailing with the prejudice that has driven both the treatment and representation of women. Nonetheless, as Marianne Hirsch (1989:10) says, 'The perspective 
of the maternal makes it difficult to reject the notion of biology and forces us to engage both the meaning of the body and the risks of what has been characterized as essentialist'.

It is in the corporeality of the body that many artists working in feminist praxis have located their work. Bothma is firmly situated within this tradition, her work bearing some conceptual and technical similarities to that, for instance, of pioneering American feminist artist Miriam Schapiro in the 1970s, who also worked on the borderlines between the beautiful, the decorative and the abject. The mass, volume, vicissitudes and spatial negotiations of bodies in relation to each other and to their accrued environment is the material substance of Bothma's works. Her deployment of the Kristevan abject, however, is observable not only in her work that more obviously embraces porous boundaries and the threats they pose (what I term abject eruption), but also in her stretching of time through her meticulous mimesis, in her making of the duration of labour - female labour, creative labour - a compulsive - even obsessional - centrepiece of her artworks. These two elements I explore in my analysis of a number of her textile-based works.

\section{Anthropomorphic interventions in the domestic}

Slippery Slope (2013) (Figure 1) is a chair that belonged to the artist's grandfather, the seat of which she subsequently removed. ${ }^{7}$ Bothma intervenes in and augments the object in various, subsequently meaningful, ways. The lack of a seat prompted the artist's selfdescribed 'intuitive' process of creating this work (Bothma 2020b). The front legs of the chair are partially sawn off to create the effect of the chair tipping forward and sinking into the floor, below the level of the floor's surface. It is apparently pulled off-balance by an organic mass of knitted material that gapes as well as stretches and extends approximately two metres by $80 \mathrm{~cm}$ in front of the chair. The knitted mass is stitched into the drilled holes for attachment of the chair seat. The knitted material is female stockings, shredded into various thicknesses by the artist to create the different textures and layers of her object.

Bothma's Slippery Slope visualises the titular figure of speech that describes, as Bothma (2020b) says, 'a complex and precarious situation that will most likely end in disaster'. The viewer's own bodily sense of stability is thrown off, uncertain in relation to the floor shared with the sculpture. Both physiologically and existentially, both viewer and sculpture question, in Bothma's (2020b) words, 'Will the weight of the knitted mass pull the chair over or can the chair right itself again?'. The floor of the gallery (or wherever the work is displayed) becomes incorporated into the artwork. The viewer's feet share the floor with the work and the viewer is thus also pulled forwards and down - the floor is suddenly dangerously porous - not so much surface as bog or wet concrete - and unstable at any given point. Able to exert influence beyond its own installation dimensions - just as it threatens the spatial boundaries of the viewer - the work pulls the whole 


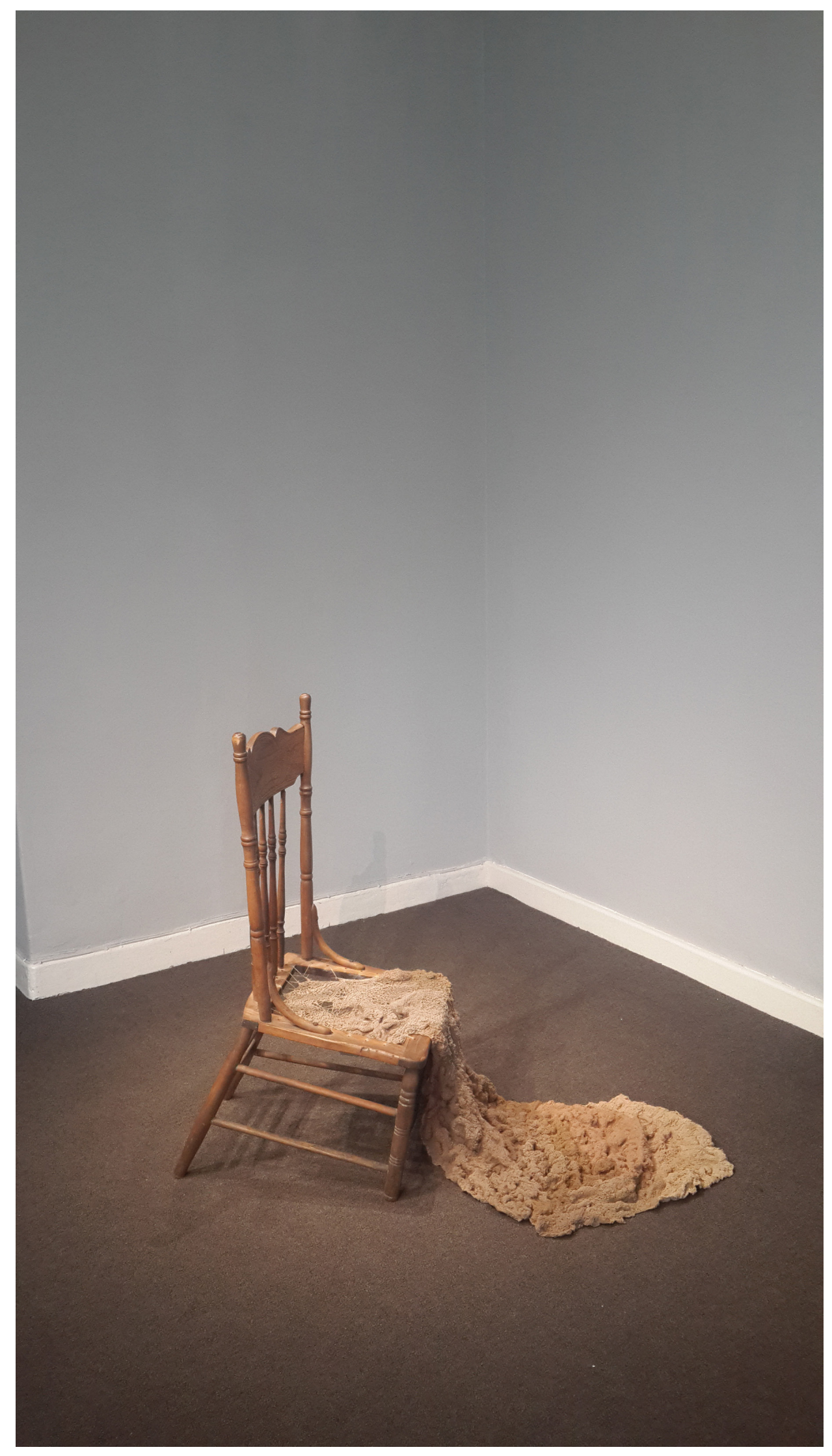

Figure $\mathbf{N}^{\mathbf{0}} \mathbf{1}$

Slippery Slope (2013). Found chair and knitted stockings. 105 x 78 x $100 \mathrm{~cm}$. Cape Town: Artist's Collection. 
exhibition space into its own gravitational field. The household is melting. Mieke Bal (2008:56) remarks that '[s]culpture is the art form par excellence that addresses the shared responsibility of and for space'. Slippery Slope's somatic and interpretative implication of the viewer in its experiential space sets the scene for the viewer being plunged into a narrative where the banal and familiar rub shoulders with the grotesque, humorous and bathetic. Writing about Doris Salcedo (an artist whom Bothma cites as an inspiration and influence), Bal (2008:56) describes Salcedo as one who 'works surfaces'. Bal (2008:43) observes that '[w]hile the things stubbornly hold on to whatever they were before, [Salcedo] takes them on, she rubs, scrapes, paints and otherwise adds to them, to abduct them from the realm of household invisibility and turn them into memorials of loss'.

These qualities are also emblematic of Bothma's work. Chairs, whose function is to hold and support a seated human body, are so dependent upon a sitter to give it meaning that chairs themselves may appear to have anthropomorphic structural aspects. The chair as a symbol of its sitter - crucially in that sitter's absence - is what Bothma invokes here. So a chair without a seat is tauntingly apurposeful; it speaks to when it was possible to hold a body, but now - perhaps wilfully - cannot. Such a chair may appear as a symbol of a person in some manner of turmoil, absent in some way to him/herself.

The anthropomorphism of Slippery Slope is also explored in Moonshine and Roses (2011) (Figure 2). An installation piece of two altered wooden chairs, set side by side yet apart, as well as mismatched, speaks about 'an odd pairing of sorts: a certain strange, dysfunctional togetherness' (Bothma 2020b). One chair was carved in half using a woodcarving tool, over three days. While carving, Bothma tied the chair together with a pair of stockings and, as she says, 'it just worked, a happy accident' (Bothma 2020b). The two halves are thus loosely yoked, held contingently together. Initially, she made small holes in the wood on both sides of the split slats of the seat area and sewed them back together with strands of her hair. Because this hair broke apart very quickly, and was totally unfeasible to attach the two halves, it enhanced the frailty of the human body and human connection that the artist was exploring in the work (Bothma 2020a).

On the second chair, Bothma has over- or re-embroidered a cluster of the overblown roses from the seat's chintzy patterned upholstery with strands of her hair. Each chair has been altered through the use of laborious processes, mimicking the tedium of the domestic space, but apparently referring here to a mismatched couple of husband and wife. The "husband" is only "standing upright", one "part" of himself irrevocably sundered from the other, the chair seat - or "soul", perhaps - fallen out from this broken frame. The "wife" may be interpreted as a person bound by social conventions (the generic, inoffensive, flowery chintz upholstery). This partner is not able perhaps to move beyond the prescribed patterns of the "established path" - the hair never deviates from the printed 


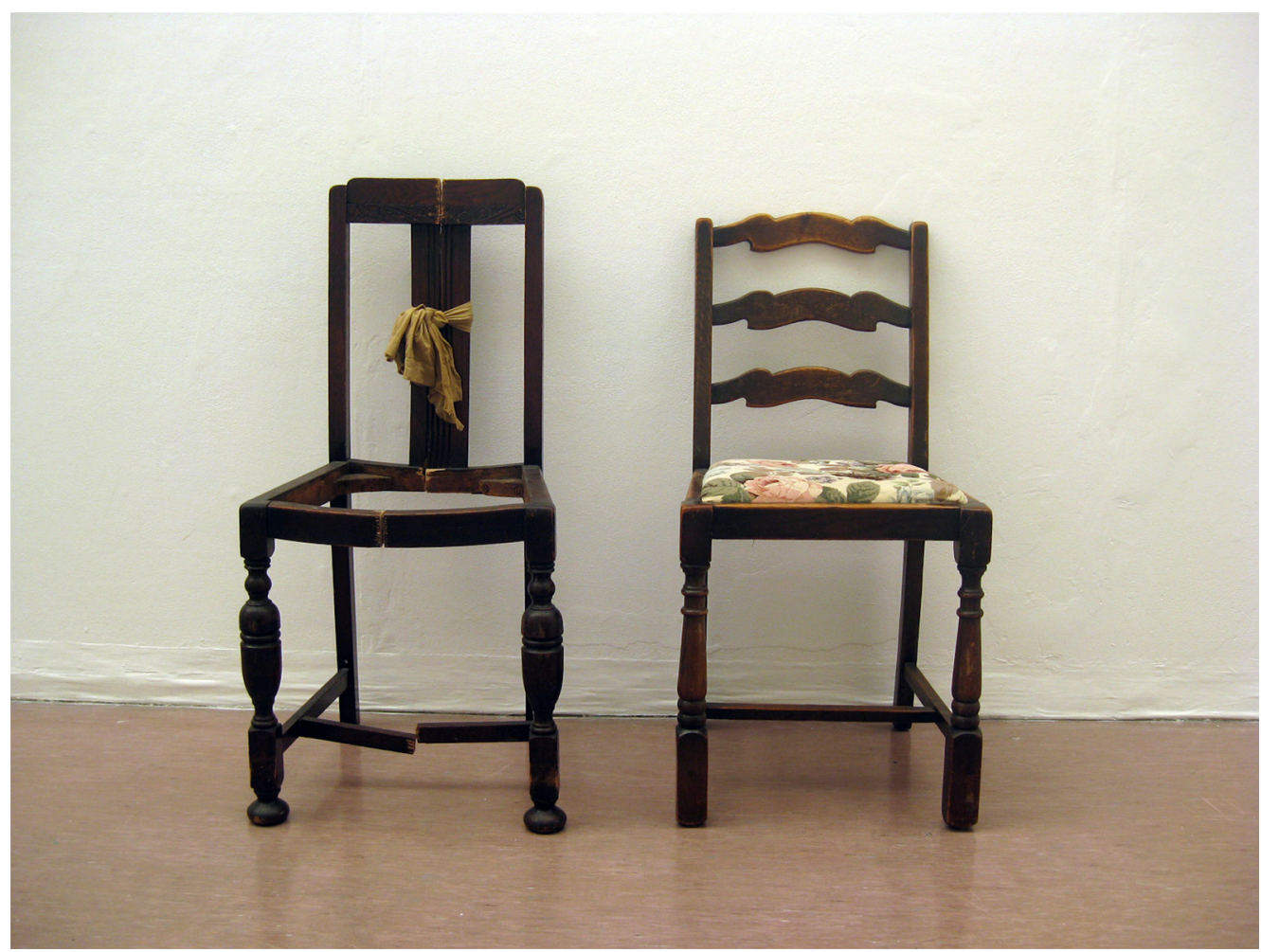

FIGURE No 2

Moonshine and Roses (2011). Chairs, hair and stocking. 38,5 x 42 ×89 cm/ 38 x 42 × 83 cm. Worcester: Private Collection. Cape Town: Artist's Collection.

pattern. The title of the work, Moonshine and Roses, refers - perhaps sardonically, perhaps bitterly - to hackneyed tropes of romance, crystallised in the 1921 song of the same title.

The anthropomorphism in Bothma's chairs - that relies upon the absence of their human users to personify disquieting characteristics that appear to be supported by loss and lack - may also be interpreted in the artist's use of stockings (or pantyhose). Stockings are close-fitting hosiery made from nylon, rayon or silk that cover the leg from the foot up to the knee, or part way up the thigh, or the full thigh. They may come in matching pairs, or be one garment that fits over the lower torso, secured by an elasticated band at the waist (such a one-piece garment is referred to particularly in North America as pantyhose). The history of stockings, particularly post-World War II, also reveals how they afford the wearer class mobility and agency in life circumstances, while bestowing a sense of luxury and sensuality that was (and may still be) appreciated by the wearer. In the 1990s, a social trend rejecting stockings' and pantyhose's "containment" was championed by a younger generation, influenced in part by the feminist movement in North America and an emerging tendency to abandon high-heeled shoes (with the attendant pairing of pantyhose) in professional spheres (Boncompagni 2012:14). 
The containment afforded by stockings is particularly for women a social nicety, a conventional requirement, specifically in particular industries and at particular time periods. While "covering" the "wayward" legs of a woman, their sheerness provides a notional, a symbolic, covering only, allowing them also to act as a form of titillation to those who would desire the woman, or fetishise the legs. Stockings may also, however, be abject, limp garments when seen apart from a pair of female legs, and it is this set of symbolisms on which Bothma focuses (Bothma 2020a). Stockings seen apart from the (female) body echo epidermal layers - skin - peeled off the body, loosely holding the ghost shape of torso and legs as they dangle - stretched, flaccid - the threads bulging or torn, so often discarded after being worn once. The similarities to a used prophylactic are not, arguably, coincidental. The transitionally abject nature of stockings also appeals to the artist: their 'supposed flesh colour ... epically failing ... Human yet not human. Of the body, yet not of the body' (Bothma 2020a). In Slippery Slope, women's stockings were cut into thin strips to be used as knitting material to create this organic mass that flows like an aggressive mudslide over the edge of the chair onto the floor. The knitted spillage has gaping holes and densely contorted clusters that fold in on themselves (Figure 3). This mass actively pulls the chair over, as if the disembowelled viscera of the anthropomorphised chair are being pulled out.

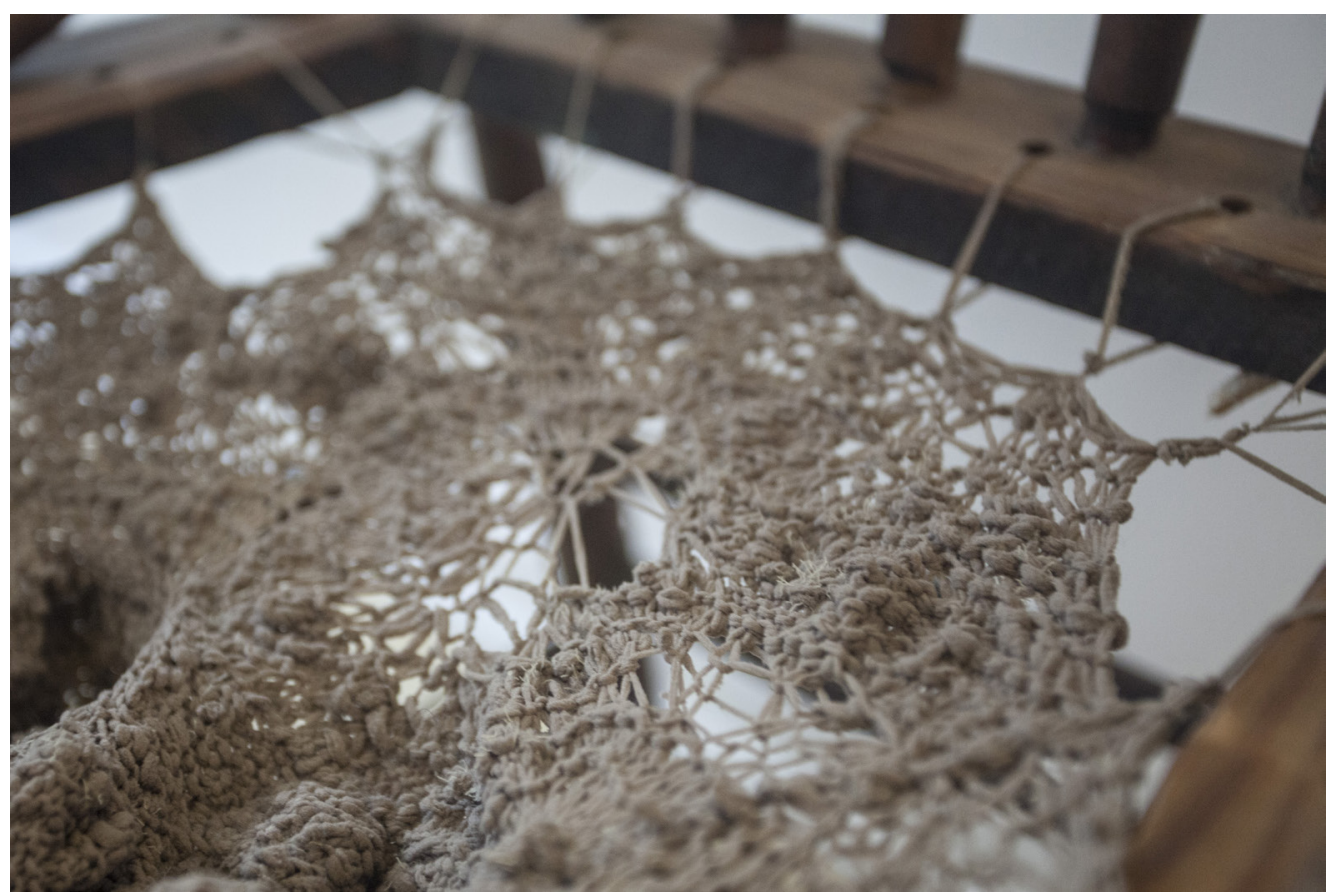

FIGURE $\mathbf{N}^{\mathbf{0}} \mathbf{3}$

Detail of Slippery Slope (2013). Found chair and knitted stockings. 105 x 78 x 100 cm. Cape Town: Artist's Collection. 


\section{Abject eruption: Stretching and breaking temporal duration}

The time that is taken to tell the tales in these works is also crucial: the temporality of the work. The labour intensive and repetitive process of creating this, and all of Bothma's textile-based works, is central to her experience of conveying the trifling, repetitive - yet cumulatively momentous - tasks associated with the care of young children and the maintenance of the family home. As she says, her works express 'the time it takes to build a relationship, the time of the domestic space, the time to grow a human, the time it takes to care for children' (Bothma 2020b).

In The Deep End (2017) (Figure 4), ${ }^{8}$ another knitted mass of stockings overflows from a wooden construction made to resemble an ironing board. An "unironable" homunculus material mass erupts from and over the ironing board as if to convey the artist's expression of rage at "mountains of ironing" for her to do. Seeking to disrupt the viewer's experience of what is often an unobserved or unconsidered task such as ironing, the artist asserts the presence and role of this task in the life of the one doing the ironing. As with Slippery Slope and Moonlight and Roses, a figure of speech is alluded to in the work's title - the homemaker or parent is "thrown off the deep end", into a life that she (the subject pronoun still more likely) did not quite anticipate would "turn out this way". The apparent ironing board becomes a diving board; the protagonist needs to "sink or swim" in "deep waters". Here the abject overflow is apparent; the artist self-consciously works with her medium to break the illusionistic, literally smooth surface of ironed laundry, of immaculate collars and cuffs.

Laura Mulvey asserts that one cannot break the illusion of a film sequence in a classic Hollywood narrative film, governed as it is by the scopic authoritarian male gaze; one cannot detach from and see outside of it. She advocates therefore for feminist strategies in alternative film making to expose the visual pleasures that are deleterious to the representation of women (Mulvey 1975). Abject eruption - seen in The Deep End and Slippery Slope - is certainly one way to break the mimetic illusion characterised by a seamless flow of images (as exemplified by film) or to break a narrative consisting of a series of acculturated tropes that interact and develop in a socially expected manner. In doing so, Bothma (2020b) asserts the artist's critical and creative role in disrupting such performances of gender. Disrupting the "smooth surface" is done literally through her aggressive knitting. 


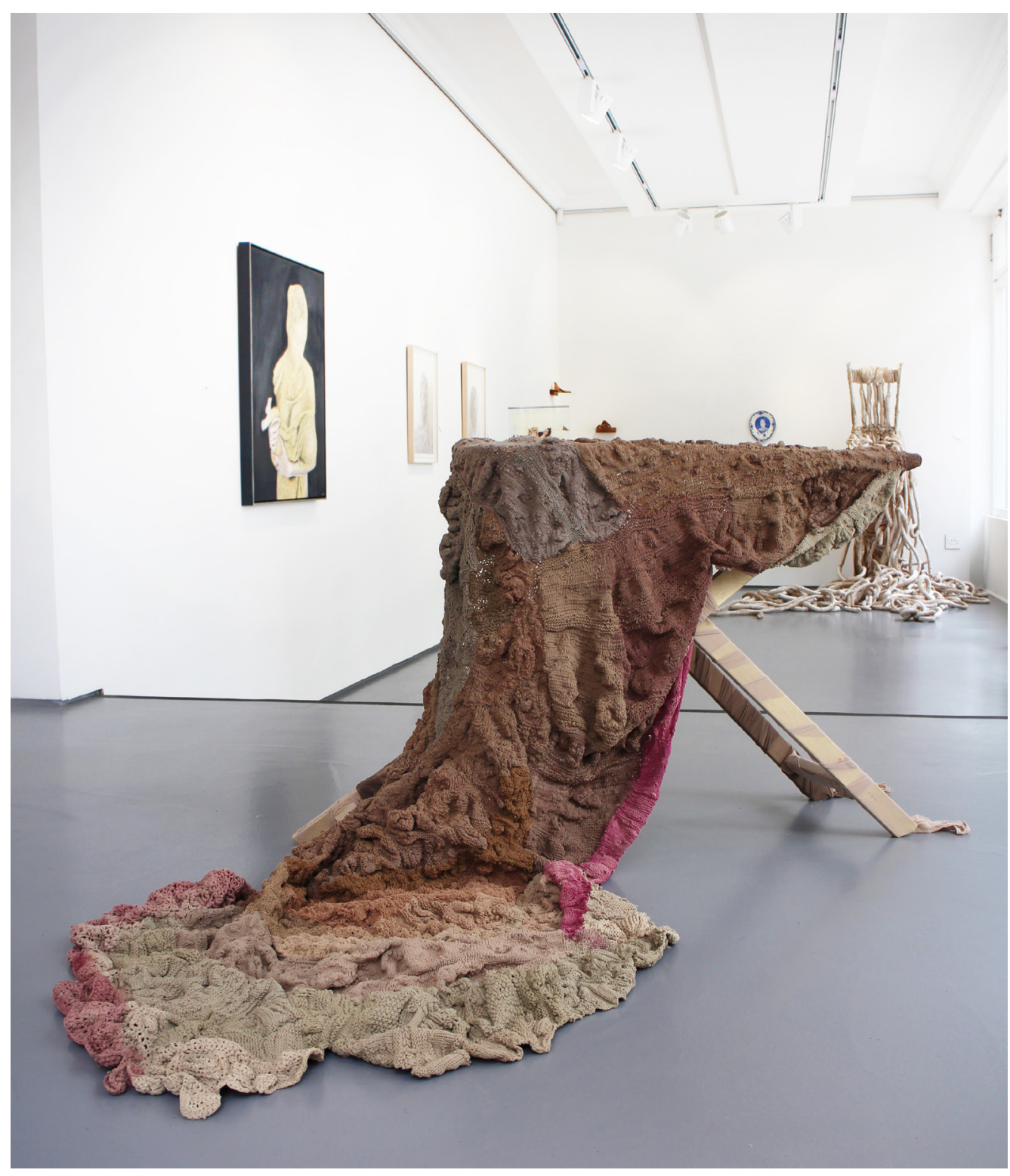

FIGURE $\mathbf{N}^{\mathbf{0}} \mathbf{4}$

The Deep End (2017). Mixed Media, 70 × 140 x 105 cm. Cape Town: Artist's Collection.

Representation as translation: Using mimesis to find alternative portraiture

Bothma also, however, self-consciously recreates a "smooth surface" in a striving after mimetic naturalism in her oil and watercolour paintings. What she foregrounds here, I believe, is an act of translation. She paints her own knitting; she paints other women's crochet. These acts of translation are not only between mediums - that also become conversations across generations, between women - but also between issues of representation concerning narratives of female subjectivity and gender roles. In the works discussed here, Bothma sets herself challenges in terms of technique and in terms of investigating uncomfortable subject matter. 


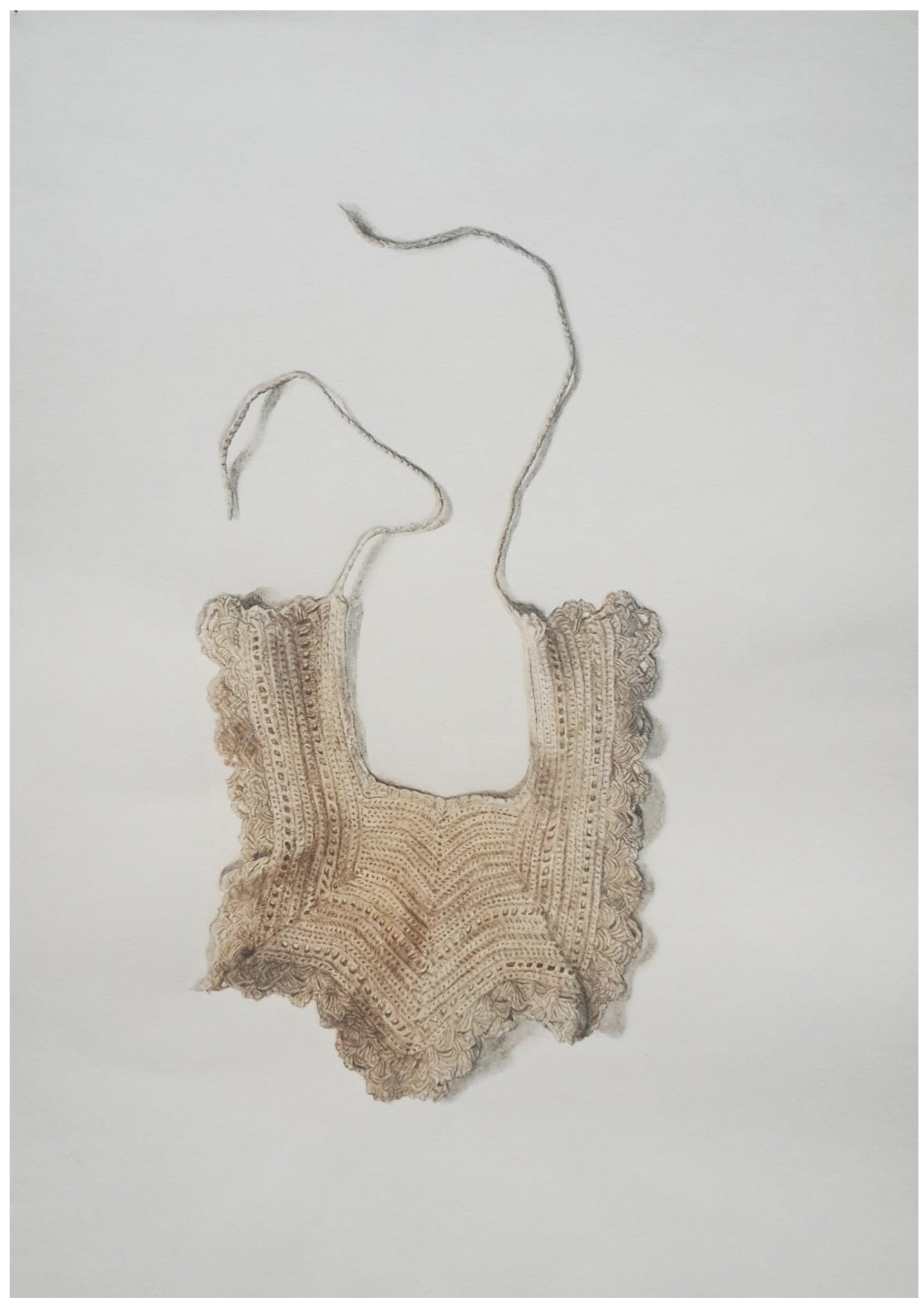

FIGURE $\mathbf{N}^{\mathbf{0}} \mathbf{5}$

From Boob to Bib I (2014). Watercolour on hahnemühle etching paper. 50 × $35 \mathrm{~cm}$. Cape Town: Artist's Collection. 
From Boob to Bib I (2014) (Figure 5) is a meticulous watercolour painting of stained cotton baby bibs trimmed with lace. These bibs are found in second hand shops, like the furniture for Bothma's anthropomorphised chairs. The artist is fascinated by what she sees as the arcane relics of an era where such time was devoted to the making of objects with such apparently abject use - with bibs, this would be the catching of drippled milk and saliva from the nursing infant. Bothma's avowed interest is in the 'abject' nature of bibs, and their now 'idiosyncratic' nature (Bothma 2020b). The painting of these bibs, however, also speaks to a mother's reflection on the growing child, to the move away from the mother in the child's individuation process, and to the mother's relationship to the child. These paintings also act therefore as a painterly reflection by the mother-artist of how the "absorption" of the intricately crocheted bib of the abject spillage may "contain" not only the infant's mess but also the ambivalent - hence messy - feelings of the mother towards the infant.

Watercolour, historically associated condescendingly with "lady painters" or with precursor sketches en plein air, becomes simultaneously both a "watery", abject medium but also a medium that allows precise and meticulous detail to be observed. The prolonged attention given to the visual dimensions of the object in her painterly process in the pair of works From Boob to Bib becomes a form of imaginative communication with the unknown woman who crocheted this bib. This is a dissecting, searching gaze that, in the meticulous washes of watercolour paint, uses water as a base (as opposed for instance to oil or acrylic paints) in order to parody the transformation of the substances deemed abject by historic discourse (such as female or infant fluids) into a more apparently "coherent", cultured expression of "art" in the form of a painterly surface. She also invites the viewer to acknowledge her patient and steely determination in terms of her technical skills, which, she believes, is most evident in her watercolours. She credits the artist Keith Dietrich, who taught her as an undergraduate student at Stellenbosch University, for this, 'His watercolours are amazing and it's probably because he told us that water colour was probably the most difficult medium you will ever do that I said well "screw this. This is a challenge"' (Sarafina 2016). Similarly, she recalls 'an art teacher at school who told me the chances of me being an artist were very slim, so I made sure I became one' (Bothma 2020a).

There is deep poignancy here: the mother is absent. The titular 'boob' is not represented, but rather the 'bib' as the souvenir object of the infant's transition towards greater bodily independence from the mother. The artist witnesses, and invites the viewer to witness, this process in the durational labour of her painting. The title may, however, be misleading in terms of what the artist was exploring in her own life at the time. Bothma was not in fact reflecting on the weaning process when painting this pair of works, but painting them 'when [she] was pregnant with [her] first-born and [she] wanted to explore the darker 
side of pregnancy and [her] underlying fears of what lay ahead' (Bothma 2020a). Her choice of these vintage items is not motivated by an en vogue retro nostalgia. Her searching, dissecting gaze over the 'idiosyncratic' qualities of preciously worked items in a baby's layette highlight their paradox, even their failure. The paradox is not ultimately that so many hours of female labour with stitch and thread went into objects that would absorb and be soiled, even "spoiled", by abject fluids from mother and child. It is that, however much ritualistic preparation might have been put into these material objects, they could not in and of themselves help to guide a woman over the threshold of childbirth to a safe delivery on the other side. They are talismans for a future, talismans particularly because they allow the abject (the long-ago stains indexically prove the arrival of the infant). But for Bothma, her meticulous technique that records every detail of stitch and stain as under a microscope allows her to take a step back, as it were, from her immersion in the experience of pregnancy, or to place a contemplative cordon around the experience. She may speak frankly, in metaphor, about the frightening, uncomfortable, undignified aspects of the experience. Yet her act of translation (from the original crochet into watercolour painting) reveals that whatever inner dialogue she may be having with the woman who crocheted the bib, her work is not a replica, and her experience must be her own. The bib as a talismanic object may therefore both offer and fail to offer succour to the artist.

In the watercolour painting Triple Threat (Figure 6) from the Balaclava series, Bothma fashions found crochet into a headpiece or mask, models it and has it photographed, and then reflects on the experience through paint. These levels of translation through representation express layers of "threat", of narratives around the roles that women embody. The eponymous balaclava here is subverted from the warm, protective wool garment that covers the head and neck, mouth and nose, but leaves the eyes clear. She explains that the action of swaddling herself in these coverings is 'very uncomfortable' and 'very claustrophobic' and therefore materially enacts the more symbolic struggles of being a woman and a mother (Sarafina 2016). She adamantly calls attention to the necessity of speaking from her own experience as both model and artist and to the gender implications of the work. She says 'I think that if a man painted that and he hadn't had the experience of having had the headpieces on himself, it would have actually changed it quite a lot because it's that actual experience' (Sarafina 2016). While the head coverings may evoke media images of the torture and degradation of political prisoners, the beautiful yet sinister coverings themselves speak more to the "gilded cage" of women's roles.

Bothma's translation of mediums is also evident in Entangled Particles (2018) (Figure 7). The mother and child are a self-portrait in oils of the artist and her young son when still nursing, heads and bodies covered - enveloping, smothered, swaddled - in a white 


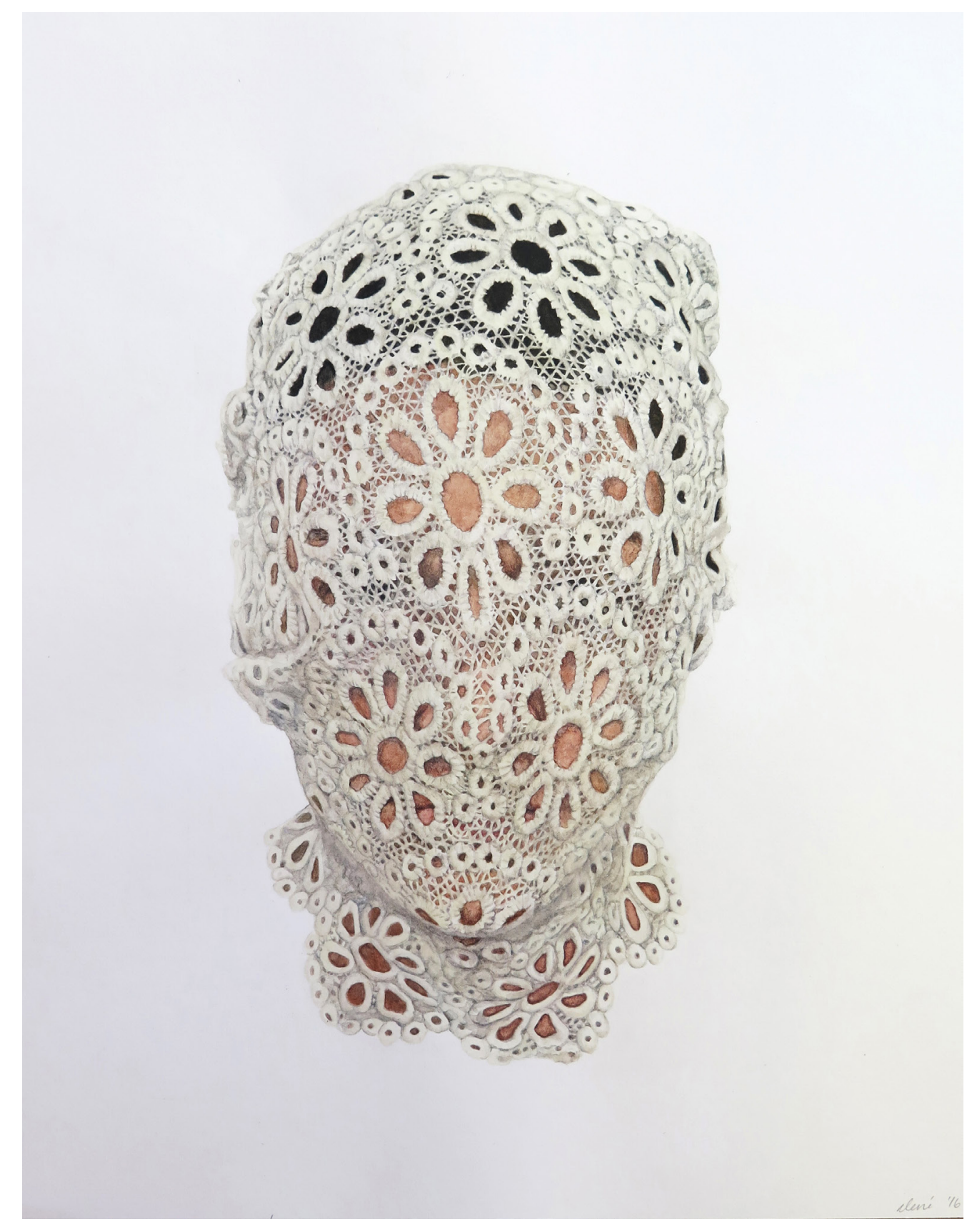

Figure $\mathbf{N}^{\mathbf{0}} \mathbf{6}$

Triple Threat from the Balaclava Series. Watercolour on paper, $31.5 \times 21.5 \mathrm{~cm}$. Unknown: Private Collection.

spread that was crocheted by the assistant of Bothma's studio mate. This work is an image of a mother's struggles with conceiving of and negotiating the discrete bounds of her own self-identity during the rearing of an infant. Beneath the covering, the mother turns her face and angles her body away from the infant, even as she is surely acutely aware of it nursing at her breast with its hands clutching her flesh. The work contends with societal conventions and expectations about the role of the mother-figure. Her 


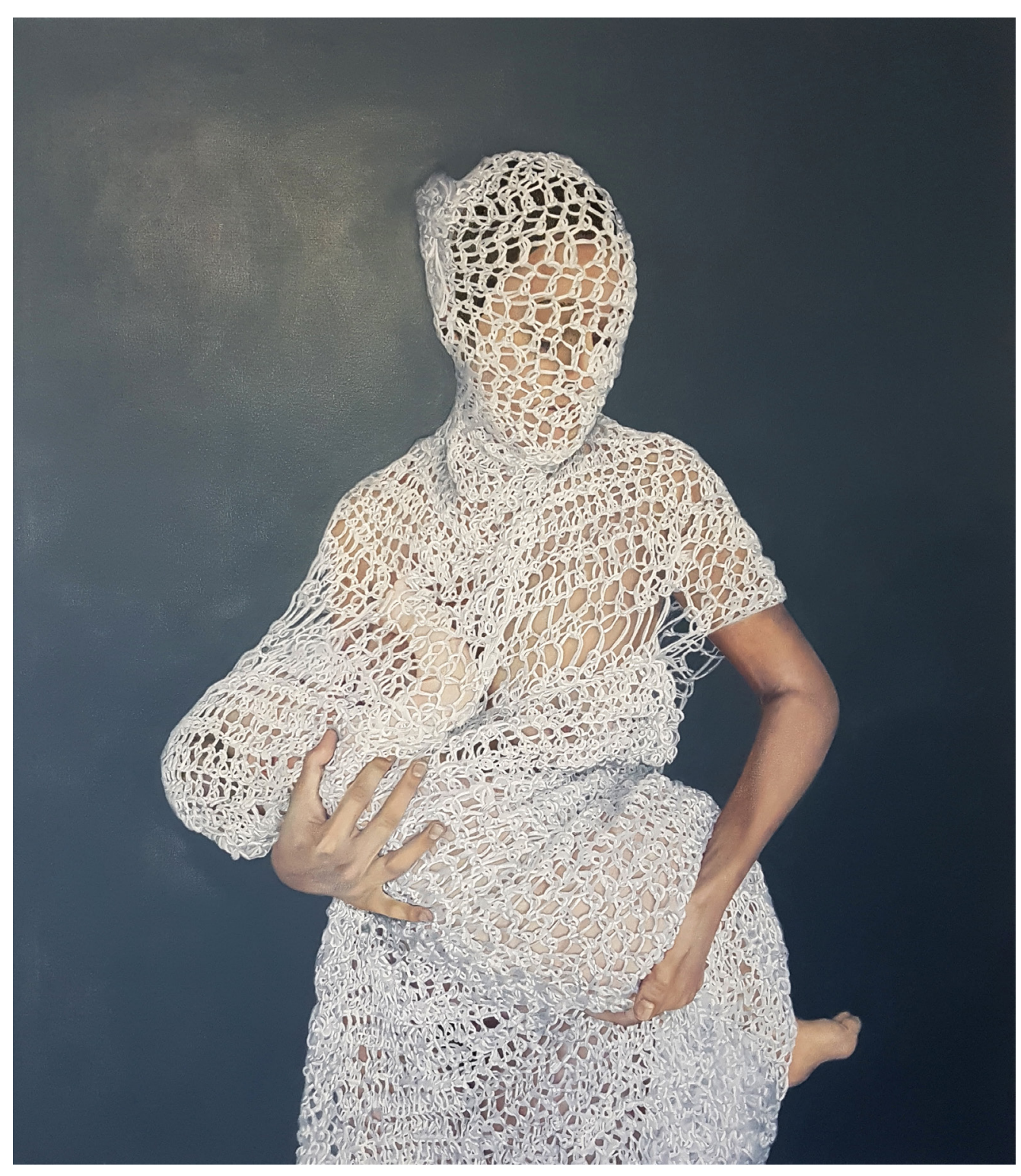

FIGURE No 7

Entangled Particles (2018). Oil on canvas, $130 \times 115$ cm. Cape Town: Private Collection.

individual identity subsumed beneath the crocheted throw or blanket, her arm forced unceremoniously through a hole torn through the throw, her infant held so close that their bodies merge in a series of corporeal bulges and curves, the mother and child here are not a sentimental, conventionalised trope, nor a religious icon of motherhood that is shaped by restrictive, patriarchal ideals of female roles. ${ }^{9}$

In these naturalistic works, Bothma's representation is more bodily, more visceral, arguably because of - not despite - the meticulously mimetic brushwork. The works are not "completed" as a photograph of her performative action, because the duration of 
labour and the repetitive paint marks need to be incorporated materially into the work. While her works using stockings or human hair as mediums materially evoke the abject, her thematic matter here in Triple Threat and Entangled Particles engages just as rigorously with issues around women's identities. The compulsive repetition, in a Freudian sense, of the knitting and knot-making that goes into the making of the mask or covering, may be read as the threat of a binding into a more conventional role of the maternal, where the woman's individual identity is sublimated to that of the mother figure, to the detriment of both mother and child. This knot-making, and the artist's translation of it, may also ward off the woman's own, at time confused, sense of self as discrete in body and psyche from her infant. Bothma (2020a) seeks to create 'discomfort' in the viewer, disregarding what she sees as a tenet of traditional portraiture, that of " smoothing over" anything remotely abject'.

\section{Hair as thread, stockings as material: Materialising women's ambivalence}

Little White Lies was created as an installation in 2011 where found vintage cotton handkerchiefs were embroidered with hair and stiffened into crumpled shapes with glue (Figure 8). These were displayed strewn - apparently discarded - along the floor of a gallery space around which the viewer had to negotiate. The lace borders and flower motifs of the original handkerchief designs have subsequently shared space on the handkerchief with various unknown stains, the state in which the artist purchased them. Now, through Bothma's augmentations, the original patterns are partly embroidered over with the artist's hair - in a similar manner to the chintzy seat cover of the "female" chair of Moonlight and Roses. The embroidered hair does not, however, follow the original patterns exactly, as it does in Moonlight and Roses, but rather hangs off the edges, threads uncut and not tidied away, its hair-like provenance maintained. The hair also moves away from following the ghosts of existing flower patterns to create spidery patterning of its own, in what hints at writing; these scribblings however remain ambiguously illegible. The artist says of them, 'These objects are repulsive and attractive at the same time; thus suggesting a certain sense of the abject while also suggesting the ambivalence that [l experience] towards the domestic' (Bothma 2020b).

Three years later, Bothma revisited these works, during the same period she was painting From Boob to Bib I and II. This time, she meticulously painted other found vintage white cotton handkerchiefs, also in muted watercolours (Figure 9). As with the artist's other naturalistic watercolours, these four untitled paintings work with a muted palette, where shadows from material folds and discoloured unwashed or unwashable stains vary only slightly in hue, and are often ambiguously indistinguishable. Bothma's naturalistic brush-work in her watercolours is noteworthy in that while it seeks a certain, almost 


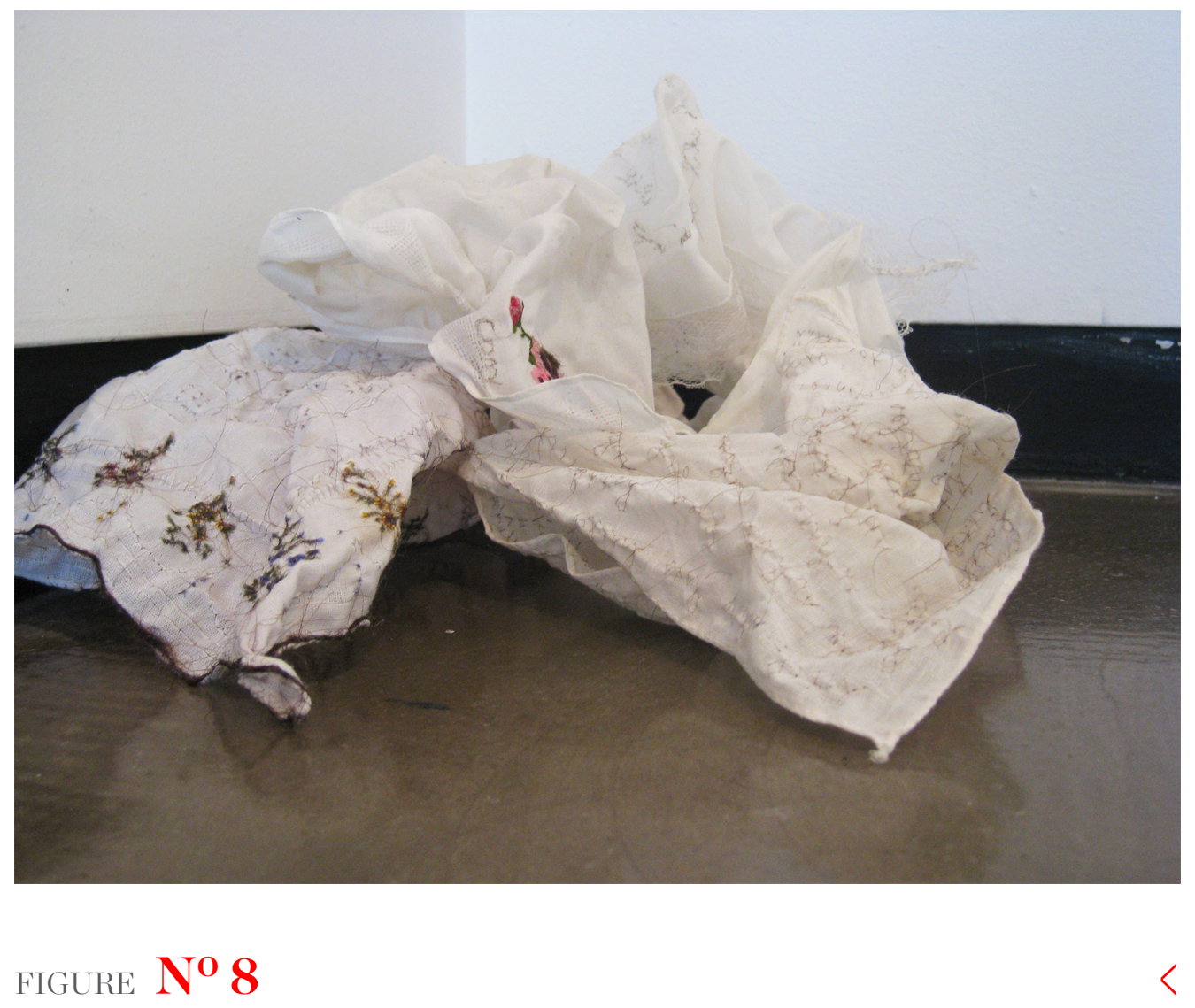

Little White Lies [installation view, detail] (2011). Handkerchiefs, hair and glue. Dimensions variable. Gallery North, Newcastle-upon-Tyne, UK, 07-23 September 2011.

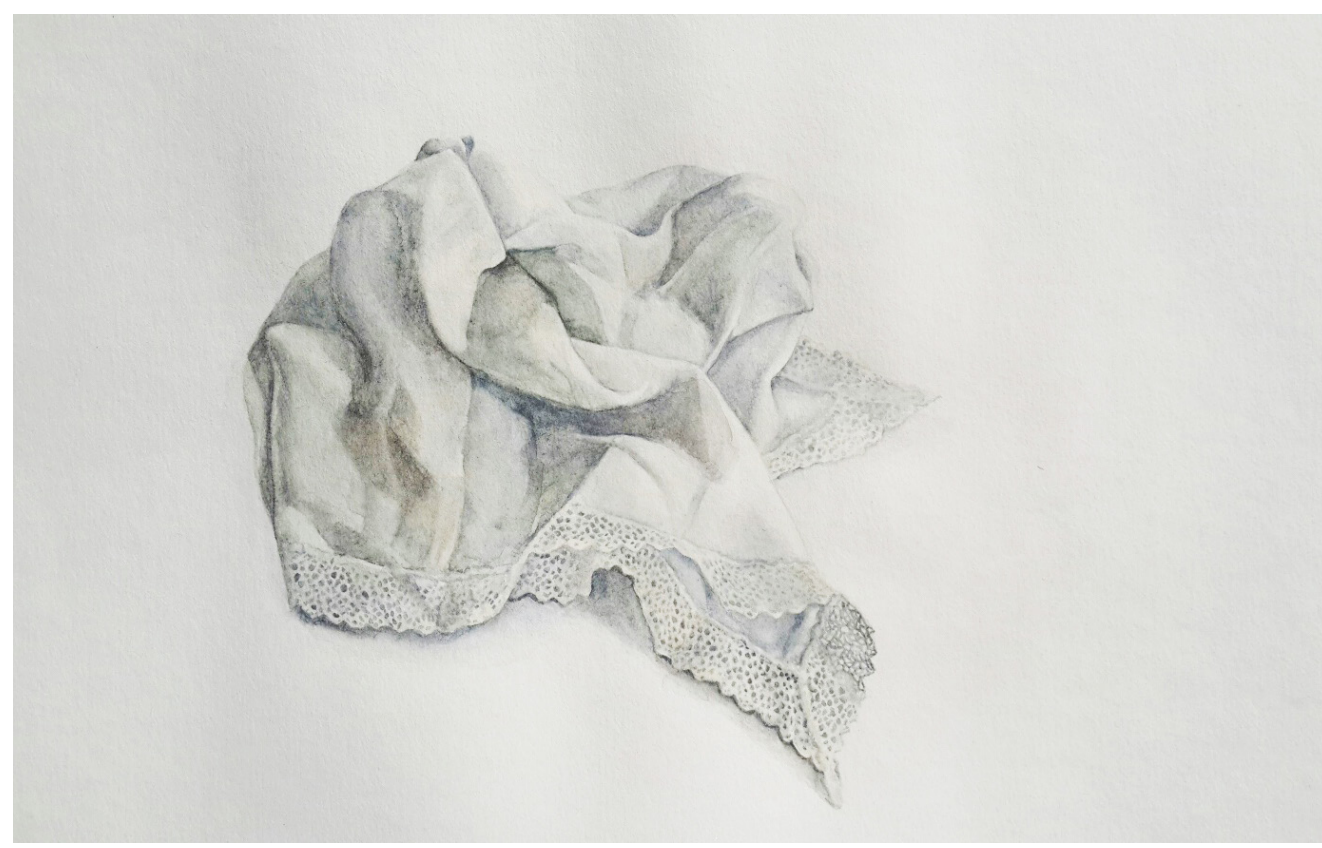

Figure $\mathbf{N}^{\mathbf{O}} \mathbf{9}$

Little White Lies IV (2014). Watercolour on hahnemühle etching paper. $39 \times 55 \mathrm{~cm}$. Cape Town: Artist's Collection. 
photographic, mimesis, this is not achieved with a performatively dramatic chiaroscuro technique. While her knitted and knotted sculptural works that re-vision found objects appear to seek a hyperbolic and abject subversion of their original functionality - a muscling into the space of the conventional domestic - her painted works of similar subject matter foreground the subtle act of translation in medium, as her creative process reflects on her own ambivalence toward her maternal role.

Here the body is nowhere represented, but everywhere present. The soiled handkerchiefs, intricately laced with the artist's hair - a nexus, web or trap of collective fantasies that shape taboos, desires and anxieties - resist narrative and yet taunt the viewer to ascribe one. Hair does not simply evoke the body, it is a literal index of it, a part that has been separated from the rest of the body. Hair is a symbol both of beauty and of bodily debris. Hair may be treasured as a keepsake, a curl of the loved one's hair kept perhaps in a locket or appropriate receptacle. Often associated with mourning for the lost object of desire, this keepsake may be of a romantic lover or of a child lost prematurely. Hair as a fetish, as a narcissistic display of adornment and seduction, may also, when 'out of place', as Mary Douglas describes (Douglas cited by Kristeva 1982:7), exemplify extreme repulsion, such as hair in a plug hole of a communal bath. Using hair as a medium threads together the realm of the abject to query issues of artistic labour, female bodies and "women's work". For Bothma, using her own hair is also establishing a relationship with her own abject.

Only represented through displaced physical matter with multiple meanings (hair), the female body here is not a rationally bounded and bordered discrete entity, but rather a form of remembrance of lost, severed and repurposed selves. The collection of secondhand furniture (furniture judged redundant by someone or sold through pressing need) souvenirs the self, particularly after going through the artist's anthropomorphising process. Collecting is always, according to Freud, a re-finding, a retrieval. The visual tracing that the viewer does of the stitched lines of hair - that follow an existing pattern on the handkerchief or that skitter out on their own path into illegible "writings" - may be a reparative process, a seeking after lost aspects of the self. They could also serve as an acknowledgement that these severances exist now only as scar tissue, worked into the delicate weave and weft of linen and cotton cloth.

This "flesh" or "skin" is arguably explored most clearly in Bothma's use of stockings, not only as knitting material, as in Slippery Slope and The Deep End, or as a queasy bodily binder of the two splintered halves of the "male" chair in Moonlight and Roses, but also as a surface canvas onto which her enquiries into gender identities and roles are stitched. In Nothing Without You (2011) (Figure 10), the gusset of a pair of pantyhose is draped over a found chair seat (the repurposed seat from the cleaved chair in Moonlight and Roses). This sheer nylon "canvas" has its pantyhose legs tied away, under and behind 


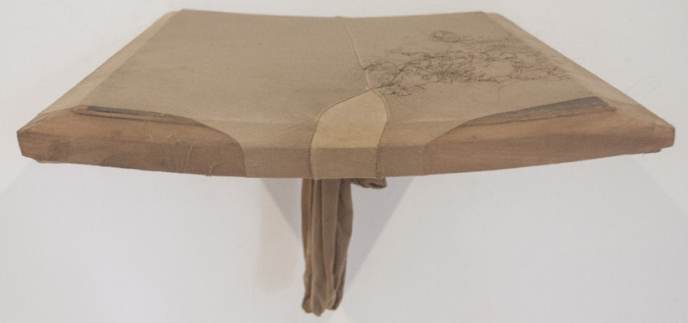

FIGURE $\mathbf{N}^{\mathbf{0}} \mathbf{1 0}$

Nothing without you (2011). Found chair seat, hair and stocking. $33 \times 36 \times 20 \mathrm{~cm}$. Cape Town: Artist's Collection.

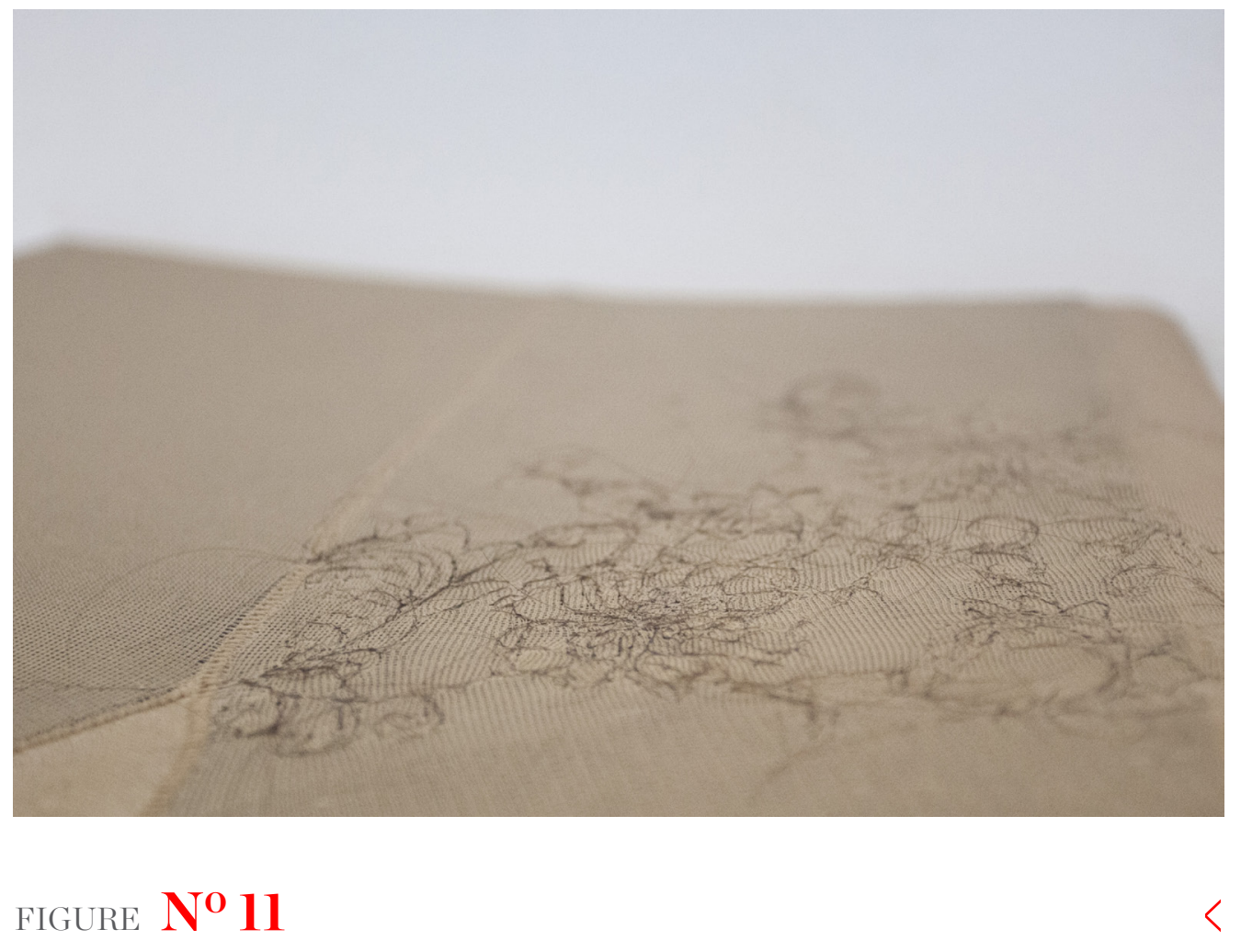

Nothing without you [detail] (2011). Found chair seat, hair and stocking. $33 \times 36 \times 20 \mathrm{~cm}$. Cape Town: Artist's Collection. 
the chair seat, which is mounted on the wall for display. The left side of the gusset is embroidered with the artist's hair into a delicate pattern of flowers and foliage (Figure 11). At this angle of viewing, the panty liner at the reinforced seam of the gusset resembles a penis laid upon the belly of a supine male body, if such a body were to be rendered in two dimensions. The dangling, creased pantyhose feet may be read as tired testicles. The embroidered hair reads in this context as ritually altered pubic hair, with one side of the body shaved, the other side tattooed or threaded into delicate "feminine" flower forms. Bothma (2020b) says about the work, 'There is a certain commingling of masculinity and femininity in this object. This merging of dualities, like male and female, familiar and strange, comfortable and awkward opens up a space for expressing ideas around the human condition'. In a manner that recalls her naturalistic paintings, the surface is stretched out for contemplative display and dissection.

Numerous representations of the female nude, as Nead (1992) describes them, reinforce a regulatory ideological containment of the scopically available female body. Nothing Without You presents an interesting alternative to this restrictive paradigm. Two of Bothma's works discussed here, Slippery Slope and Moonlight and Roses, may be said to "begin" interpretatively with the absence of the chair seat - its "soul" or "guts" - from the works. It is this absence that prompted the directions of the artistic interventions - the angry spillage of aggressive knitted mass in Slippery Slope and the surrendered broken halves of the "male" chair of Moonlight and Roses. From this point of view, the chair seat suspended in the exhibition space at the viewer's waist or pelvis level comes to read as an almost sublime, transcendent moment of integration. 'I am nothing without you' may not necessarily be the plaintive lament of a stranded blonde whose man has abandoned her in one of the Hollywood classic film sequences that Mulvey would have analysed. It could read as a somatically known acknowledgement of the negotiable balances of apparent binaries that psychological health needs to exist within one individual.

\section{Conclusion}

Bothma paints her own crochet work in oils and watercolours; she embroiders on found objects, from furniture to linen; she translates the apparently abject shed bodily waste that is strands of human hair into delicate thread stitched into cloth, weaving illegible text. Her making again becomes an act of meaning in itself. Her self-declared interest in speaking to specific interactions and tensions between the various roles of women that I detail here brushes - again in a self-aware manner - with deliberately compulsive and obsessive detailing as an attempt to document and to give meaning to the life of a mother of young children. Rather than a jouissance in the abject substances with which a 
mother deals, these abject substances and processes are included, alongside other materials and processes, in the artist's oeuvre, as they are in her life. The abject, however, also opens up possibilities towards the reconfiguration of the conventional, allowing the artist's works to surface as a testament - however ambivalent, however richly ambivalent - to her own life experience.

Bothma's work therefore offers a rich exploration of the relationship of the abject to women's ambivalence. Her "bad” knitting, abject eruptions and spillage, meticulous mimesis, repetitive acts, and durational extension are not unconnected choices of medium and technique, but rather all propel the movement from the viewer's awareness of the abject to an awareness of the complexities of the female psyche. Mulvey brings together Freud's source of fetishism - the mother's body - and Marx's - the erasure of the value of the worker's labour - to make the salient observation that '[b]oth become the unspeakable, and the unrepresentable, in commodity culture: repression of the mother's body, repression of labour power as a source of value' (Mulvey 1996:14). Bothma may be seen to speak and to represent both of these in her working away at the "surfaces" of female subjectivities and female ambivalence.

\section{Acknowledgements}

My sincere thanks to llené Bothma for her interest in my project and willingness to correspond with me. She also provided me with the images for publication. I am grateful for the comments by the anonymous reviewers on the first draft of this article.

\section{Notes}

1. Bothma received a BA in Fine Art and an MA in Fine Art from Stellenbosch University, and in 2011, a second MA in Fine Art (with distinction) from Northumbria University at Newcastle-upon-Tyne, United Kingdom. She says that 'some kind of lightbulb went on when I was studying in England', after which her work changed dramatically, and began to be shaped around the concerns and techniques that she continues to develop today (Sarafina 2016). After returning from England, she lectured for three years while supporting her husband's studies to become an advocate. A week after resigning from her lecturing position to pursue art-making full time, she discovered that she was pregnant with their first child. She is now a full-time artist and mother to two children. She has been nominated as a finalist in the 2007 Sasol New Signatures Competition, the 2012 Vuleka Art Competition and the 2016 Barclays L'Atelier. Participating in group exhibitions since 2000, Bothma has held five solo exhibitions (four of which were in Cape Town and one in Port Elizabeth).

2. What has been published to date on Bothma's work is limited to artist's statements and publicity material from 99 Loop (the gallery that represents the artist). No journalistic articles, online blogs or reviews have, at the time of writing, engaged with her work beyond the publicising of her exhibitions 
and the summarising of the show in terms of the talking points provided by herself or her gallery. One interview with the artist has been published online (see Sarafina 2016). From the artist's cultural history, one may introduce an analysis based upon the interrogation and subversion of ordentlikheid ('respectability') - culturally sanctioned, historically derived conventions for Afrikaans females. I offer in this article, however, a more general introduction to her works that takes cognisance of the various, more generically global, feminist strategies that her work deploy, in acknowledgment of the themes that the artist herself identities as significant to her praxis.

3. The force of the abject is to be understood in relationship with the philosophies, epistemologies, codes of morality and intellectual tools that favour the production of the Cartesian or Enlightenment rational, coherent subject. In psychoanalytic terms, the abject threatens a reestablishment of our "primal repression" of the lived experience (now "lost" memory) of not differentiating between or being differentiated from "self" and "other". The abject is a precondition for the necessary narcissism of egoformation, often explained symbolically as the "mirror stage", which is Jacque Lacan's formulation (Kristeva 1982:13).

4. There has been substantial engagement with, elaboration on and critique of Kristeva's concept of the abject in particular, and her literary linguistic practice more broadly. Philosopher Judith Butler (1989:104) for instance contends that 'In the course of arguing that the semiotic contests the universality of the Symbolic, Kristeva makes several theoretical moves which end up consolidating the power of the Symbolic and paternal authority generally' and does not therefore provide as subversive a strategy as Kristeva proposes.

5. For instance, Womanhouse, the influential feminist initiative led by Judy Chicago and Miriam Schapiro in 1972, brought together woman artists, community members and female students from their Feminist Arts Program at the California Institute of Arts to create installation and performance art works from the stuff of the house-space to engage with issues of femininity and domesticity.

6. While Bothma's work may certainly be analysed in relation to the Freudian unheimlich (uncanny), this is not a direction I pursue in this article. The artist herself works with the concept, with what she calls 'my uncanny' (Bothma 2020a).

7. Bothma reworked Slippery Slope subsequent to its exhibition; it no longer exists in the form as discussed in this article.

8. Bothma reworked The Deep End subsequent to its exhibition; it no longer exists in the form as discussed in this article.

9. This representation of the artist and her infant son Pieter-Steph speaks to, but is not, the Madonna and her immaculately conceived male child, Christ. This is a secular portrait of mother and son, with the artist and mother as protagonist, negotiating the entangled threads of the distinct subjectivities of each person.

\section{References}

Bal, M. 2007. Earth Aches: The Aesthetics of the cut, in Doris Salcedo Shibboleth, edited by Tate Publishing. Milbank, London: Tate:40-63.

Boncompagni, T. 2012. For Pantyhose, It's back to work. New York Times. 162 (55952):14.

Bothma, I. 2020a. Personal correspondence with the author. [Electronic mail]. 27 July. 
Bothma, I. 2020b. Ilené Bothma. [O]. Available:

http://www.ilenebothma.com/.

Accessed 12 February 2020.

Hirsch, M. 1989. The Mother/Daughter plot: Narrative, Psychoanalysis, Feminism. Bloomington, Indiana: Indiana University Press.

Butler, J. 1989. The Body Politics of Julia Kristeva. Hypatia 3(3):104-118.

Kristeva, J. 1982. Powers of Horror: An Essay on Abjection. Translated by LS Roudiez. New York: University of Columbia Press.

Maintz, V \& Pollock, G. 2000. Introduction, in Work and the Image 1: Work, craft and labour: Visual representations in Changing Histories, edited by V Maintz and G Pollock. Aldershot and Burlington, Vermont: Ashgate Publishing Ltd:1-12.

Mulvey, L. 1975. Visual pleasure and narrative cinema. Screen 16(3):6-18.

Mulvey, L. 1996. Fetishism and curiosity. London: Indiana University Press.

Nead, L. 1992. The female nude: Obscenity and sexuality. London: Routledge.

Sarafina Magazine. 2016. A conversation with llené Bothma. [O]. Available: https://sarafinamagazine.com/2016/09/29/a-conversation-with-ilene-bothma/ Accessed 12 February 2020. 